\title{
Prescription practices in the treatment of agitation in newly hospitalized Chinese schizophrenia patients: data from a non- interventional naturalistic study
}

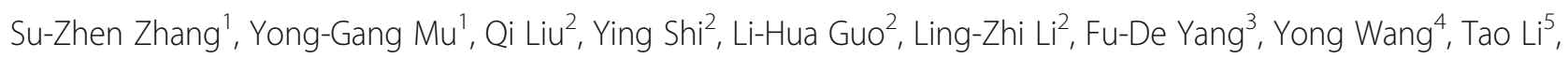
Qi-Yi Mei ${ }^{6}$, Hong-Bo He ${ }^{7}$, Zhi-Yu Chen ${ }^{8}$, Zhong-Hua Su' ${ }^{9}$, Tie-Bang Liu ${ }^{10}$, Shi-Ping Xie ${ }^{11}$, Qing-Rong Tan ${ }^{12}$, Jin-Bei Zhang ${ }^{13}$, Cong-Pei Zhang ${ }^{14}$, Hong Sang ${ }^{15}$, Wei-Feng Mi $^{2^{*}}$ and Hong-Yan Zhang ${ }^{2^{*}}$

\begin{abstract}
Background: Data on the pharmacological management of acute agitation in schizophrenia are scarce. The aim of this study is to investigate the prescription practices in the treatment of agitation in Chinese patients with schizophrenia.

Methods: We conducted a large, multicenter, observational study in 14 psychiatry hospitals in China. Newly hospitalized schizophrenia patients with the PANSS-EC total score $\geq 14$ and a value $\geq 4$ on at least one of its five items were included in the study. Their drug treatments of the first 2 weeks in hospital were recorded by the researchers.

Results: Eight hundred and 53 patients enrolled in and 847 (99.30\%) completed the study. All participants were prescribed antipsychotics, 40 (4.72\%) were prescribed benzodiazepine in conjunction with antipsychotics and 81 were treated with modified electric convulsive therapy (MECT). Four hundred and 12 (48.64\%) patients were prescribed only one antipsychotic, in the order of olanzapine (120 patients, 29.13\%), followed by risperidone (101 patients, 24.51\%) and clozapine (41 patients, 9.95\%). About 435 (51.36\%) participants received antipsychotic polypharmacy, mostly haloperidol + risperidone (23.45\%), haloperidol+ olanzapine (17.01\%), olanzapine+ ziprasidone (5.30\%), haloperidol + clozapine (4.37\%) and haloperidol + quetiapine (3.90\%). Binary logistic regression analysis suggests that a high BARS score (OR 2.091,95\%Cl 1.140-3.124), severe agitation (OR 1.846, 95\%CL 1.266-2.693), unemployment or retirement (OR 1.614, 95\%CL 1.189-2.190) and aggressiveness on baseline (OR 1.469, 95\%CL 1.032-2.091) were related to an increased antipsychotic polypharmacy odds. Male sex (OR 0.592, 95\%CL 0.436-0.803) and schizophrenia in older persons (age $\geq 55$ years, OR $0.466,95 \% C L$ 0.240-0.902) were less likely to be associated with antipsychotic polypharmacy.

Conclusion: The present study demonstrates that monotherapy and polypharmacy display equally common patterns of antipsychotic usage in managing agitation associated with schizophrenia in China. The extent and behavioral activities of agitation and several other factors were associated with polypharmacy.
\end{abstract}

Keywords: Schizophrenia, Agitation, Prescription

\footnotetext{
* Correspondence: weifengmi@bjmu.edu.cn; hongyanzhang@bjmu.edu.cn ${ }^{2}$ Peking University Sixth Hospital, Peking University Institute of Mental Health, NHC Key Laboratory of Mental Health (Peking University), National Clinical Research Center for Mental Disorders (Peking University Sixth Hospital), 51, Huayuan Bei Road, Beijing 100191, China

Full list of author information is available at the end of the article
}

(c) The Author(s). 2019 Open Access This article is distributed under the terms of the Creative Commons Attribution 4.0 International License (http://creativecommons.org/licenses/by/4.0/), which permits unrestricted use, distribution, and reproduction in any medium, provided you give appropriate credit to the original author(s) and the source, provide a link to the Creative Commons license, and indicate if changes were made. The Creative Commons Public Domain Dedication waiver (http://creativecommons.org/publicdomain/zero/1.0/) applies to the data made available in this article, unless otherwise stated. 


\section{Background}

Agitation among psychiatric inpatients, particularly those with schizophrenia or bipolar disorder, is a major public health concern. It can rapidly escalate to aggression and violence and poses a considerable risk to the patients themselves and to others $[1,2]$. Recent studies indicate that agitation significantly contributes to rising medical costs and caregiver burden $[3,4]$. In the United States alone, agitated patients with schizophrenia accounted for 900,000 annual visits to psychiatric emergency services, representing $21 \%$ of all psychiatric emergency visits [5]. According to the State of Acute Agitation at Psychiatric Emergencies in Europe (STAGE) study, schizophrenia was the underlying in $47.27 \%$ (78 of 165) of psychiatric agitation episodes [6]. In China, we previously screened 1400 newly hospitalized patients with schizophrenia, finding that $60.92 \%$ (853 of 1400) were agitated [7]. Current psychiatric recommendations on agitation promote the early use of verbal de-escalation techniques [2, 8]. However, a considerable percentage of schizophrenia patients with agitation still require psychopharmacological approaches, including typical or first-generation antipsychotic drugs, atypical or second-generation antipsychotic drugs, and benzodiazepines $[9,10]$. Depending on the patient's level of cooperation or the perceived onset of the drug effect, there are four routes available in clinical practice: inhalation, oral administration, intramuscular injection, and intravenous injection. Therefore, an array of pharmacological options administered via different routes exists, providing physicians with numerous treatment alternatives.

Typical antipsychotics have proven effectiveness in the treatment of agitation, particularly haloperidol [10]. However, considering the high risk of extrapyramidal side effects and their superior efficacy and lower adverse effect burden, atypical antipsychotics are highly preferred in clinical practice $[8,9]$. Although monotherapy is recommended in clinical practice guidelines for the use of antipsychotics in the management of schizophrenia [11, 12], polypharmacy is common, ranging from 20.4 to $69.6 \%$ across different countries [13-16]. In a 2002 study investigating the factors influencing the prescription of antipsychotics to patients with schizophrenia in China, about 25.9\% of 3523 patients received polypharmacy [17]. In Hong Kong, a survey investigated the current prescribing patterns of agitation in emergency departments for patients without a specific diagnosis on record [18]. There are no published data on prescription practices for schizophrenia with agitation in China. Thus, the aim of our study was to reveal the prescription practices in the treatment of agitation in Chinese patients with schizophrenia.

\section{Methods}

\section{Study design and subjects}

This study was part of the Investigation of Prevalence and Treatment of Agitation in Newly Hospitalized
Schizophrenia in China (IPTASC, Hongyan Zhang Group Investigators).

This observational, multicenter, cross-sectional study is aimed to explore the patterns of antipsychotic use for agitation among newly hospitalized Chinese schizophrenia patients and to the factors possibly associated with the prescription pattern. Data specific to this report were collected between June 2014 to December 2014. All of the patients in this study were consecutively recruited from 14 psychiatric hospitals in representative regions of China (see the author affiliations). The study was conducted after obtaining approval from the ethics committees of Peking University Sixth Hospital and all other participating hospitals. All participants provided written informed consent from the patients themselves or their legal guardians (if involuntary admission) prior to the enrollment.

Inclusion criteria were: age $\geq 18$ years; Han ethnicity; newly hospitalized (admission within $24 \mathrm{~h}$ ) in one of the 14 hospitals; diagnosis of schizophrenia or hallucinatory paranoid state based on the International Statistical Classification of Diseases and Related Health Problems, 10th revision (ICD-10); Clinical Global ImpressionSeverity (CGI-S) score $\geq 4$, and Positive and Negative Syndrome Scale-Excited Component (PANSS-EC) score $\geq 14$ and at least one of its five items was $\geq 4$. Exclusion criteria were: had comorbidity that caused agitation, such as substances use disorder, central nervous system disease, including Parkinson's disease, Alzheimer's disease, other types of dementia, encephalitis and meningitis and general medical conditions (e.g., thyrotoxicosis, hypoglycemia, brain traumas.); incapable of completing the survey because of mental or physical dysfunction were also excluded; non-schizophrenia patients; withdrew informed consent.

Data on antipsychotic patterns and potential related factors were obtained from the patients and their caregivers through a specially designed questionnaire. The questionnaire includes basic general demographics, clinical characteristics including the course of schizophrenia, age of onset, number of lifetime hospitalizations, admission patterns (whether voluntary hospitalization or not), CGI-S scores, BARS scores, PANSS-EC scores, and MOAS scores and treatment information. After admission, the first two parts would be completed in $24 \mathrm{~h}$ by his/her psychiatrist. Two weeks later, the same psychiatrist re-diagnosed the patients to exclude any nonschizophrenic patients and collect the treatment information. A brief enrollment IPTASC study is presented in Additional file 1: Figure S1.

\section{Statistical analysis}

After the surveys were completed, all questionnaires were sent to Peking University Sixth Hospital for data 
analysis. The copyright of the dataset belongs to Peking University Sixth Hospital. Differences in demographics, clinical characteristics, and possible associated factors were calculated between the antipsychotic monotherapy group and the polypharmacy group. We adopted the $t$ test and the $\chi^{2}$ test to examine theses factors in relation to antipsychotic prescription practices. Factors that were significantly different between groups were analyzed using a binary logistic regression model. For all statistical analyses, differences were considered significant at a two-tailed $p<0.05$. All statistical analyses were performed with SPSS 16.0 software (SPSS, Chicago, IL).

\section{Results}

\section{Demographic and clinical characteristics}

Of 1512 patients screened, we enrolled 853 patients who met the inclusion criterion of agitation. Because 6 individuals did not provide prescription information, 847 participants (99.30\%; male, $51.00 \%$ ) were included in the final analysis. Among them, 435 (51.36\%) were subject to polypharmacy during the first 2 weeks. The demographic and disease characteristics of the participants, along with those of the polypharmacy and monotherapy groups, are presented in Table 1. Mean age was $34.62 \pm$ 11.79 years. Most of the participants (70.84\%) had less than 12 years of education (education level lower than college) and $36.48 \%$ were married. Approximately threequarters $(77.57 \%)$ were involuntarily hospitalized and the mean lifetime number of hospitalizations was $1.96 \pm$ 3.10. About half (51.36\%) of the participants were employed and the mean duration of schizophrenia was $8.20 \pm 8.80$ years. Approximately $47.46 \%$ of the participants had severe agitation and $70.84 \%$ had aggressive behavior(s) at baseline (Table 1).

\section{Prescription patterns and frequency of antipsychotic medications}

All participants were prescribed antipsychotics. Also, 40 $(4.72 \%)$ were prescribed benzodiazepine in conjunction with antipsychotics and 81 were treated with modified electroconvulsive therapy (MECT). The most frequently selected route of administration was oral alone, accounting for over half of the 847 prescriptions. The next most common administration route was a combination of oral and intramuscular injections (39.91\% of prescriptions). Only 47 patients $(5.55 \%)$ received intramuscular drug injection alone (Table 2). None took antipsychotics through intravenous administration. Among $847 \mathrm{pa}$ tients, only 2 were orally administered haloperidol, with 99.33\% (300 of the 302 patients) intramuscularly administered the drug.

As shown in Tables 2, 412 patients (48.64\%) were prescribed only one antipsychotic (either in single or multiple formulations), including 371 patients who were prescribed a second-generation antipsychotic. The most commonly prescribed agents were olanzapine (120, $29.13 \%$ ) in the monotherapy group, risperidone (101, 24.51\%), and clozapine (41, 9.95\%) (Table 3).

About half of the participants $(435,51.36 \%)$ were treated with antipsychotic polypharmacy, with 396 (46.57\%) receiving two different antipsychotics, 38 (4.49\%) receiving three different antipsychotics, and $1(0.12 \%)$ receiving four different antipsychotics. The frequencies of multiple antipsychotics were in the following order: haloperidol + risperidone $(23.45 \%)$, haloperidol + olanzapine (17.01\%), olanzapine + ziprasidone (5.30\%), haloperidol + clozapine (4.37\%), and haloperidol + quetiapine (3.90\%). There were significant differences between the polypharmacy and monotherapy groups in sex, age, admission pattern, living alone, aggressiveness at baseline, severe agitation, and BARS score $(p<0.01$, Table 1$)$.

\section{Characteristics associated with antipsychotic polypharmacy}

The results of binary logistic regression analysis are shown in Table 4. A high BARS score (odds ratio [OR] 2.091, 95\% confidence interval [95\%CI] 1.1400-3.124), severe agitation (OR 1.846, 95\%CI 1.266-2.693), unemployment or retirement (OR 1.614, 95\%CI 1.189-2.190), and aggressiveness at baseline (OR 1.469, 95\%CI 1.032-2.091) were suggested to be related to an increased antipsychotic polypharmacy odds, whereas male sex (OR 0.592, 95\%CI $0.436-0.803$ ) and schizophrenia in older persons (age $\geq 55$ years, OR $0.466,95 \%$ CI $0.240-0.902$ ) were less likely to be associated with antipsychotic polypharmacy.

\section{Discussion}

To our knowledge, this is the first report of prescription patterns among schizophrenia patients with agitation in China. The current expert guidelines and research data $[9,10,19,20]$ indicate that, in the management of agitation due to a psychiatric illness, second-generation antipsychotics (risperidone, olanzapine, ziprasidone) are to be selected as first-line agent. In our study, most patients (94.81\%) received atypical antipsychotics. The widespread use of second-generation antipsychotics may be due to their well-known superiority in terms of adverse effects. Specifically, the most used antipsychotic was haloperidol, identified in 302 patients (35.66\%), followed by olanzapine in 276 (32.59\%) and risperidone in 258 (30.46\%). Given its easy accessibility and its long track record of efficacy in the management of agitation, haloperidol is an important treatment choice in cases of limited resources. Previous studies reported economic status as a major factor in antipsychotic prescription in Chinese outpatients with schizophrenia [17]. Consequently, the lower price of haloperidol may also have contributed to its popularity. 
Table 1 Demographic and clinical characteristics of respondent patients

\begin{tabular}{|c|c|c|c|c|c|}
\hline & $\begin{array}{l}\text { Overall } \\
(n=847)\end{array}$ & $\begin{array}{l}\text { Monotherapy } \\
(n=412)\end{array}$ & $\begin{array}{l}\text { Polypharmacy } \\
(n=435)\end{array}$ & $x^{2} / t$ & $p$ \\
\hline \multicolumn{6}{|l|}{$\overline{S e x}, n(\%)^{a}$} \\
\hline Male & $432(51.00)$ & 234 & 198 & \multirow[t]{2}{*}{9.97} & \multirow[t]{2}{*}{0.002} \\
\hline Female & $409(48.29)$ & 177 & 232 & & \\
\hline Age, mean (SD), y & $34.62(11.79)$ & $35.38(12.52)$ & $33.92(11.02)$ & 1.78 & $0.075^{*}$ \\
\hline \multicolumn{6}{|l|}{ Schizophrenia in older persons, $\mathrm{n}(\%)^{\mathrm{b}}$} \\
\hline Yes & $51(6.02 \%)$ & 34 & 17 & \multirow[t]{2}{*}{7.23} & \multirow[t]{2}{*}{0.007} \\
\hline No & 796(93.98\%) & 368 & 411 & & \\
\hline \multicolumn{6}{|l|}{ Educational level, $n(\%)^{c}$} \\
\hline$\leq$ High school & $600(70.84)$ & 288 & 312 & \multirow[t]{2}{*}{0.40} & \multirow[t]{2}{*}{0.526} \\
\hline$\geq$ College & $242(28.57)$ & 122 & 120 & & \\
\hline \multicolumn{6}{|l|}{ Marital status, $\mathrm{n}(\%)^{\mathrm{d}}$} \\
\hline Married & $309(36.48)$ & 142 & 167 & \multirow[t]{4}{*}{1.64} & \multirow[t]{4}{*}{0.65} \\
\hline Single & $444(52.42)$ & 225 & 219 & & \\
\hline Divorced & $79(9.33)$ & 38 & 41 & & \\
\hline Widowed & $10(1.18)$ & 5 & 5 & & \\
\hline \multicolumn{6}{|l|}{ Living alone, $n(\%)^{e}$} \\
\hline Yes & $40(4.72)$ & 28 & 12 & \multirow[t]{2}{*}{7.12} & \multirow[t]{2}{*}{0.005} \\
\hline No & 802(94.69) & 381 & 421 & & \\
\hline \multicolumn{6}{|l|}{ Employment, $\mathrm{n}(\%)^{\mathrm{f}}$} \\
\hline Employed & $435(52.76)$ & 187 & 248 & \multirow[t]{2}{*}{11.06} & \multirow[t]{2}{*}{0.001} \\
\hline Unemployed or retired & $400(47.23)$ & 218 & 182 & & \\
\hline \multicolumn{6}{|l|}{ Health insurance ${ }^{g}$} \\
\hline Yes & 297(35.06) & 137 & 160 & \multirow[t]{2}{*}{0.94} & \multirow[t]{2}{*}{0.332} \\
\hline No & $542(63.99)$ & 269 & 273 & & \\
\hline \multicolumn{6}{|l|}{ Admission pattern ${ }^{h}$} \\
\hline Voluntary hospitalization & 179(21.13) & 65 & 114 & \multirow[t]{2}{*}{14.23} & \multirow[t]{2}{*}{$1.62 \mathrm{E}-4$} \\
\hline Involuntary hospitalization & $657(77.57)$ & 343 & 314 & & \\
\hline Age at onset, mean (SD), y & $26.53(9.66)$ & $27.15(10.34)$ & 25.94(8.88) & 1.81 & $0.071^{*}$ \\
\hline Course of schizophrenia, mean (SD), y & $8.20(8.80)$ & $8.39(8.95)$ & $8.03(8.01)$ & 0.58 & $0.566^{*}$ \\
\hline Number of hospitalizations, mean (SD) & $1.96(3.10)$ & $1.95(3.09)$ & $1.97(3.11)$ & -0.09 & $0.932^{*}$ \\
\hline CGI score, mean (SD) & $5.38(0.81)$ & $5.38(0.77)$ & $5.38(0.84)$ & 0.12 & $0.908^{*}$ \\
\hline BARS score, mean (SD) & $5.43(1.19)$ & $5.20(1.14)$ & $5.65(1.18)$ & -5.60 & 2.87E-8 \\
\hline \multicolumn{6}{|c|}{ Antipsychotics used in the previous week, $n(\%)^{i}$} \\
\hline Yes & $350(41.32)$ & 163 & 187 & 2.99 & 0.084 \\
\hline No & $465(54.90)$ & 245 & 220 & & \\
\hline Aggressiveness on baseline (MOAS $\geq 4), n($ & & & & & \\
\hline Yes & $600(70.84 \%)$ & 273 & 327 & 11.58 & 0.001 \\
\hline No & 247(29.16) & 135 & 95 & & \\
\hline Severe agitation & & & & & \\
\hline Yes & $402(47.46 \%)$ & 161 & 241 & 22.61 & $1.98 \mathrm{E}-6$ \\
\hline No & $445(52.54 \%)$ & 251 & 194 & & \\
\hline
\end{tabular}

Notes: ${ }^{\text {a }}$ Six participants $(0.71 \%)$ did not provide this information. ${ }^{\mathrm{b}}$ Seventeen participants (2.01\%) did not provide this information. ${ }^{\mathrm{c}}$ Five participants $(0.6 \%)$ did not provide this information. ${ }^{d}$ Five participants $(0.59 \%)$ did not provide this information. ${ }^{e}$ Five participants $(0.59 \%)$ did not provide this information. ${ }^{\mathrm{f}}$ Twelve participants (1.42\%) did not provide this information. ${ }^{\mathrm{g}}$ Eight participants $(0.94 \%)$ did not provide this information. ${ }^{\mathrm{h}}$ Eleven participants (1.30\%) did not provide this information. ${ }^{i}$ Thirty two participants (3.79\%) did not provide this information. ${ }^{*}$ T test CGI Clinical Global Impressions-Severity, BARS Behavioral Activity Rating Scale, MOAS Modified Overt Aggression Scale 
Table 2 Prescription patterns and administration routes of psychotic medications for respondent patients

\begin{tabular}{|c|c|c|}
\hline & $\begin{array}{l}\text { Overall } \\
(n=847)\end{array}$ & $\begin{array}{l}\text { Schizophrenia In } \\
\text { older persons } \\
(n=51)\end{array}$ \\
\hline \multicolumn{3}{|l|}{ Prescription patterns, $n(\%)$} \\
\hline Monotherapy & $412(48.64)$ & $34(66.67)$ \\
\hline Typical antipsychotic only & $41(4.84)$ & $5(9.80)$ \\
\hline Atypical antipsychotic only & $371(43.80)$ & $29(56.86)$ \\
\hline Polypharmacy & 435(51.36) & 17(33.33) \\
\hline Typical+ Typical & $3(0.35)$ & 0 \\
\hline Typical+ Atypical & 287(33.88) & $13(25.49)$ \\
\hline Atypical+ Atypical & $145(17.12)$ & $4(284.31)$ \\
\hline \multicolumn{3}{|l|}{ Concomitant medications, $n(\%)$} \\
\hline Benzodiazepines & $40(4.72 \%)$ & $2(3.92)$ \\
\hline MECT, $n(\%)$ & $81(9.56 \%)$ & $2(3.92)$ \\
\hline \multicolumn{3}{|l|}{ Administration route, $n(\%)$} \\
\hline Oral route alone & $462(54.55 \%)$ & $30(58.82)$ \\
\hline $\begin{array}{l}\text { A combination of oral and } \\
\text { intramuscular injections route }\end{array}$ & 338(39.91\%) & $14(27.45)$ \\
\hline Intramuscular injections route alone & $47(5.55 \%)$ & $7(13.73)$ \\
\hline
\end{tabular}

The American Association for Emergency Psychiatry (AAEP) and World Federation of Societies of Biological Psychiatry (WFSBP) consensus guidelines recommend oral antipsychotics over intramuscular injections if possible $[9,12]$. Our study found that 385 of 847 patients (45.5\%) received intramuscular injections. An unstable course of illness, irritability, and uncooperativeness promote the use of intramuscular injections in agitation management. Additionally, intramuscular administration is preferred by clinicians for rapid and effective treatment. Note that a systematic review of studies from 2001 to 2010 showed that oral and intramuscular medications are equally effective in rapidly reducing psychotic agitation in the emergency department [21]. Nonetheless, further studies are needed.

Approximately $51.36 \%$ of patients were prescribed antipsychotic polypharmacy. Our rate of polypharmacy is much higher than the rate from a 2011 report on schizophrenia in China in both inpatients and outpatients [17] and the rate from a 2015 report in a Hong Kong emergency department [18]. There are two possible reasons for this difference: (1) newly hospitalized patients with agitation usually have more severe symptoms, increasing the difficulty of treatment; and (2) the desire to enhance or accelerate treatment efficacy [22] or to reduce the dose of antipsychotics with certain adverse effects $[23,24]$.

The key factors associated with polypharmacy in the present study were a high BARS score (OR 2.091, 95\%CI 1.1400-3.124) and severe agitation (OR 1.846, 95\%CI 1.266-2.693). The seven-point BARS assesses behavioral activities in agitated patients with high reliability and convenience, with results ranging from sedation, to normal activity, to agitation [25]. Agitation is an established short-term factor associated with physical aggression [26]. The assessment of behavioral activities in agitated patients at an early stage may help to identify the risk of aggression and suggest specific treatment interventions. According to a recent survey of 583 community-dwelling patients with schizophrenia or bipolar disorder, the most common experience of agitation was in the form of internal feelings, including uneasiness, restlessness, and nervousness [27]. A qualitative study with healthcare professionals defined three states of agitation, with aggression or violence only included in severe agitation [28]. Better assessment and effective management of severe agitation could potentially avoid aggressive episodes. In agreement with this, several studies and published consensus guidelines have focused on acute episodes of severe agitation [29-31]. We also found that unemployment or retirement (OR 1.614, 95\%CI 1.189-2.190) and aggressiveness at baseline (OR 1.469, 95\%CI 1.032-2.091) were associated with polypharmacy. Unemployment may be a sign of disease severity.

In contrast with previous research [32, 33], we observed a negative association between polypharmacy and male sex (OR 0.592, 95\%CI 0.436-0.803). In a study of 43 severely agitated patients with schizophrenia spectrum disorders, there was a sex effect in the poor treatment response in women [30]. Furthermore, some studies reported that women committed more physical assaults than men during the 4-week inpatient treatment $[34,35]$. These two findings could imply a tendency toward polypharmacy in women. Our findings are consistent with existing research that older people with

Table 3 The five most common used psychotic medications for respondent patients

\begin{tabular}{|c|c|c|c|c|c|}
\hline \multicolumn{2}{|l|}{$\begin{array}{l}\text { Total } \\
(n=847)\end{array}$} & \multicolumn{2}{|c|}{$\begin{array}{l}\text { Monotherapy } \\
(n=412)\end{array}$} & \multicolumn{2}{|l|}{$\begin{array}{l}\text { Polypharmacy } \\
(n=435)\end{array}$} \\
\hline \multicolumn{2}{|c|}{ Medication, $n(\%)$} & \multicolumn{2}{|c|}{ Medication, $n(\%)$} & \multicolumn{2}{|l|}{ Medication, $n(\%)$} \\
\hline Haloperidol & $302(35.66)$ & Oanzapine & $120(29.13)$ & Haloperidol+ Risperidone & $102(23.45)$ \\
\hline Olanzapine & $275(32.47)$ & Risperidone & $101(24.51)$ & Haloperidol+ Olanzapine & $74(17.01)$ \\
\hline Risperidone & 259(30.58) & Clozapine & $41(9.95)$ & Olanzapine+ Ziprasidone & 23(5.29) \\
\hline Clozapine & $125(14.76)$ & Quetiapine & $36(8.74)$ & Haloperidol+ Cozapine & $19(4.37)$ \\
\hline Ziprasidone & $105(12.40)$ & Haloperidol & $28(6.80)$ & Haloperidol+ Quetiapine & $17(3.90)$ \\
\hline
\end{tabular}


Table 4 Characteristics associated with antipsychotic polypharmacy for respondent patients

\begin{tabular}{llll}
\hline & OR & $95 \% \mathrm{Cl}$ & $P$ \\
\hline BARS score & 2.091 & $1.140-3.124$ & $3.16 \mathrm{E}-4$ \\
Severe agitation & 1.846 & $1.266-2.693$ & 0.001 \\
Unemployed or retired & 1.614 & $1.189-2.190$ & 0.002 \\
Aggressiveness on baseline (MOAS $\geq 4)$ & 1.469 & $1.032-2.091$ & 0.033 \\
Schizophrenia in older persons & 0.466 & $0.240-0.902$ & 0.023 \\
Living alone & 0.438 & $0.209-0.919$ & 0.029 \\
Male sex & 0.592 & $0.436-0.803$ & 0.001 \\
\hline
\end{tabular}

schizophrenia (age $\geq 55$ years) are less likely to receive antipsychotic polypharmacy [32, 33]. In contrast to younger schizophrenia patients, older patients are more prone to adverse effects, including extrapyramidal side effects and metabolic syndrome [36]. It is advisable to start with a single, low initial dose and titrate slowly. A study comprising 8792 elderly schizophrenia patients suggested that the combined use of first- and second-generation antipsychotics was positively associated with relapse (OR 1.70, 95\%CI 1.25-2.31) [37]. Besides the consideration of safety, older patients are less prone to aggressive episodes [38].

\section{Limitations}

There are some limitations to this study. First, we lack data on the use of non-pharmacological interventions (verbal deescalation, physical restraint, and seclusion) to calm agitated patients, which may have some interactions with the prescription pattern. Thus, limited data are available to provide insight into the relationship between non-pharmacological and pharmacological interventions. Second, there is potential for a discrepancy between prescribing decisions in practice. The reasons for the clinicians' prescribing decision processes and patients' preferences for prescriptions were not explored. The confounding effects of these differences could not thus be addressed. Third, the dose of each drug was not taken into consideration, mainly because the prescriptions of newly hospitalized agitated schizophrenia patients are not stable in the first 2 weeks. Fourth, legal status or past history of crime was not measured.

\section{Conclusions}

With a large sample size and a large number of participating sites involved in a standardized assessment, our findings have some important clinical implications. The present study demonstrates that monotherapy and polypharmacy are equally common in antipsychotic application in managing agitation associated with schizophrenia in China. The extent and behavioral activities of agitation and several other factors were associated with polypharmacy. Additional factors should be evaluated in future studies.

\section{Additional file}

Additional file 1: Figure S1. Enrollment IPTASC Study. (PDF 22 kb)

\section{Acknowledgements}

We are grateful for the generosity of time and effort by the patients and their families and all of the researchers from the 14 hospitals (see the author affiliations) who made this study possible.

\begin{abstract}
Authors' contributions
Author SZZ wrote the first draft of the manuscript, performed literature searches, and conducted analyses. Authors YGM, QL, YS, LHG and LZL performed literature searches and conducted analyses. Authors FDY, YW, TL, QYM, HBH, ZYC, ZHS, TBL, SPX, QRT, JBZ, CPZ and HS contributed to data management and analysis. Authors WFM and HYZ designed the study and wrote the protocol. All authors contributed to and approved the final manuscript.
\end{abstract}

\section{Funding}

This work was supported by the Capital Health Development Research (2016-2-4112), National Science and Technology Major Project for IND (investigational new drug, 2018ZX09734-005) and the Beijing Municipal Commission of Science and Technology Clinical Application Special Fund (Z181100001718157).

Availability of data and materials

The datasets used during the current study are available from the corresponding author on reasonable request.

Ethics approval and consent to participate

The study protocol was approved by the ethics committees of Peking University Sixth Hospital and all other participating hospitals. Patients themselves or their legal guardians (if involuntary admission) had signed their informed consent of the study.

Consent for publication

Not applicable.

Competing interests

The authors declare that they have no competing interests.

\section{Author details}

${ }^{1}$ Department of Psychiatry, Huzhou 3rd Hospital, Huzhou 313000, Zhejiang, China. ${ }^{2}$ Peking University Sixth Hospital, Peking University Institute of Mental Health, NHC Key Laboratory of Mental Health (Peking University), National Clinical Research Center for Mental Disorders (Peking University Sixth Hospital), 51, Huayuan Bei Road, Beijing 100191, China. ${ }^{3}$ Beijing HuiLongGuan Hospital, Huilong guan Changping District, Beijing 100096, China. ${ }^{4}$ Shanghai Mental Health Center, 600,Wanpingnan Street, Shanghai 200030, China. ${ }^{5}$ West China Hospital of Sichuan, 37, Guoxue Street, Wuhou District, Chengdu 610041, Sichuan, China. '5uzhou Guangji Hospital, 285, Guangji Street, Gusu District, Suzhou 215008, Jiangsu, China. ${ }^{7}$ Guangzhou Psychiatric Hospital, 36, Mingxin Street, Liwan District, Guangzhou 510000, Guangdong, China. ${ }^{8}$ The Seventh People's Hospital of Hangzhou, 305, Tianmushan Street, Xihu District, Zhejiang 310013, Hangzhou, China. ${ }^{9}$ Jining Mental Hospital, 1, Jidai Street, Jining 272000, Shandong, China. ${ }^{10}$ Shenzhen Kangning Hospital, 1080,Cuizhu Street, Luohu District, Shenzhen 518003, China. ${ }^{11}$ Nanjing Brain Hospital, 264,Guangzhou Road, Gulou District, Nanjing 210029, Jiangsu,

China. ${ }^{12}$ Xijing Hospital of Forth Military Medical University, 15, Changlexi Road, Xi'an 710032, Shanxi, China. ${ }^{13}$ The Third Affiliated Hospital of Sun Yat-sen University, 600, Tianhe Road, Tianhe District, Guangzhou 510630, Guangdong, China. ${ }^{14}$ Harbin First Specific Hospital, 217, Hongwei Road, Harbin 150056, Heilongjiang, China. ${ }^{15}$ Sixth Hospital of Changchun, 4596, Beihuan Road, Changchun 130052, Jilin, China. 
Received: 15 January 2019 Accepted: 23 June 2019

Published online: 10 July 2019

\section{References}

1. Hankin CS, Bronstone A, Koran LM. Agitation in the inpatient psychiatric setting: a review of clinical presentation, burden, and treatment. J Psychiatr Pract. 2011;17:170-85.

2. Holloman G, Zeller S. Overview of project BETA: best practices in evaluation and treatment of agitation. West J Emerg Med. 2012;13:1-2.

3. Serrano-Blanco A, Rubio-Valera M, Aznar-Lou I, et al. In-patient costs of agitation and containment in a mental health catchment area. BMC Psychiatry. 2017;17:212.

4. Blanthornhazell S, Gracia A, Roberts J, Boldeanu A, Judge D. A survey of caregiver burden in those providing informal care for patients with schizophrenia or bipolar disorder with agitation: results from a European study. Ann General Psychiatry. 2018;17:8.

5. Zeller SL, Rhoades RW. Systematic reviews of assessment measures and pharmacologic treatments for agitation. Clin Ther. 2010;32:403-25.

6. San L, Marksteiner J, Zwanzger P, et al. State of acute agitation at psychiatric emergencies in Europe: the STAGE study. Clin Pract Epidemiol Ment Health. 2016;12:75-86.

7. Mi W, Zhang S, Liu Q, et al. Prevalence and risk factors of agitation in newly hospitalized schizophrenia patients in China: an observational survey. Psychiatry Res. 2017;253:401-6.

8. Garriga M, Pacchiarotti I, Kasper S, et al. Assessment and management of agitation in psychiatry: expert consensus. World J Biol Psychiatry. 2016;17: 86-128.

9. Hays H, Jolliff HA, Casavant MJ. The psychopharmacology of agitation: consensus statement of the American association for emergency psychiatry project BETA psychopharmacology workgroup. West J Emerg Med. 2012;13:536.

10. San L, Arranz B, Escobar R. Pharmacological management of acutely agitated schizophrenic patients. Curr Pharm Des. 2005;11:2471-7.

11. Lehman AF, Lieberman JA, Dixon LB, et al. Practice guideline for the treatment of patients with schizophrenia, second edition. Am J Psychiatry. 2004;161:1-56.

12. Wobrock T. World Federation of Societies of biological psychiatry (WFSBP) guidelines for biological treatment of schizophrenia, part 2: update 2012 on the long-term treatment of schizophrenia and management of antipsychotic-induced side effects. World J Biol Psychiatry. 2013;6:132-91.

13. Roh D, Chang JG, Yoon S, Kim CH. Antipsychotic prescribing patterns in first-episode schizophrenia: a five-year comparison. Clin Psychopharmacol Neurosci. 2015;13:275-82.

14. Gaviria AM, Franco JG, Aguado V, et al. A non-interventional naturalistic study of the prescription patterns of antipsychotics in patients with schizophrenia from the Spanish Province of Tarragona. PLoS One. 2015;10: e0139403.

15. Kim HY, Lee HW, Jung SH, et al. Prescription patterns for patients with schizophrenia in Korea: a focus on antipsychotic Polypharmacy. Clin Psychopharmacol Neurosci. 2014;12:128-36.

16. Robinson DG, Schooler NR, John M, et al. Prescription practices in the treatment of first-episode schizophrenia spectrum disorders: data from the national RAISE-ETP study. Am J Psychiatr. 2015;172:237-48.

17. Si TM, Shu L, Li KQ, et al. Factors that influence the prescription of antipsychotics for patients with schizophrenia in China. Clin Psychopharmacol Neurosci. 2011;9:122-8.

18. Chan EW, Tang C, Lao KS, et al. Management of acute agitation in Hong Kong and comparisons with Australasia. Emerg Med Australas. 2016;27:542-8.

19. Hasan A, Falkai $P$, Wobrock $T$, et al. World Federation of Societies of biological psychiatry (WFSBP) guidelines for biological treatment of schizophrenia - a short version for primary care. Int J Psychiatry Clin Pract. 2017:21:82.

20. Zhang H, Wang G, Zhao J, et al. Intramuscular ziprasidone versus haloperidol for managing agitation in Chinese patients with schizophrenia. J Clin Psychopharmacol. 2013;33:178-85.

21. Gault TI, Gray SM, Vilke GM, Wilson MP. Are oral medications effective in the management of acute agitation? J Emerg Med. 2012;43:854-9.

22. Sud P, Nelson L, Diller D. Intravenous Droperidol or olanzapine as an adjunct to midazolam for the acutely agitated patient: a multicenter, randomized, double-blind, placebo-controlled clinical trial. Ann Emerg Med. 2013;61:72-81.
23. Pandurangi AK, Dalkilic A. Polypharmacy with second-generation antipsychotics: a review of evidence. J Psychiatr Pract. 2008;14:345-67.

24. Gallego JA, Nielsen J, De HM, Kane JM, Correll CU. Safety and tolerability of antipsychotic polypharmacy. Expert Opin Drug Saf. 2012;11:527.

25. Swifta RH, Harriganb EP, Cappelleria JC, Kramerc D, Chandlerd LP. Validation of the behavioural activity rating scale (BARS)TM: a novel measure of activity in agitated patients. J Psychiatr Res. 2002;36:87-95.

26. Szabo KA, White CL, Cummings SE, Wang RS, Quanbeck CD. Inpatient aggression in community hospitals. CNS Spectr. 2015;20:223-30.

27. Roberts J, Gracia Canales A, Blanthorn-Hazell S, Craciun Boldeanu A, Judge D. Characterizing the experience of agitation in patients with bipolar disorder and schizophrenia. BMC Psychiatry. 2018;18:104.

28. Rubio-Valera M, Huerta-Ramos E, Baladon L, et al. Qualitative study of the agitation states and their characterization, and the interventions used to attend them. Actas Esp Psiquiatr. 2016;44:166-77.

29. Peisah C, Chan DKY, Mckay R, Kurrle SE, Reutens SG. Practical guidelines for the acute emergency sedation of the severely agitated older patient. Intern Med J. 2011;41:651-7.

30. Walther S, Moggi F, Horn H, et al. Rapid tranquilization of severely agitated patients with schizophrenia spectrum disorders: a naturalistic, rater-blinded, randomized, controlled study with oral haloperidol, risperidone, and olanzapine. Pharmacopsychiatry. 2013;34:124-8.

31. Fang $\mathrm{M}$, Chen $\mathrm{H}$, Li LH, et al. Comparison of risperidone oral solution and intramuscular haloperidol with the latter shifting to oral therapy for the treatment of acute agitation in patients with schizophrenia. Int Clin Psychopharmacol. 2012;27:107-13.

32. Suokas JT, Suvisaari JM, Haukka J, Korhonen P, Tiihonen J. Description of long-term polypharmacy among schizophrenia outpatients. Soc Psychiatry Psychiatr Epidemiol. 2013;48:631-8.

33. Morrato EH, Dodd S, Oderda G, Haxby DG, Allen R, Valuck RJ. Prevalence, utilization patterns, and predictors of antipsychotic polypharmacy: experience in a multistate Medicaid population, 1998-2003. Clin Ther. 2007; 29:183-95.

34. Krakowski M, Czobor P. Gender differences in violent behaviors: relationship to clinical symptoms and psychosocial factors. Am J Psychiatry. 2004;161: 459-65.

35. Serper MR, Goldberg BR, Herman KG, et al. Predictors of aggression on the psychiatric inpatient service. Compr Psychiatry. 2005;46:121-7.

36. Jeste DV, Maglione JE. Treating older adults with schizophrenia: challenges and opportunities. Schizophr Bull. 2013;39:966.

37. Talaslahti T, Alanen HM, Hakko H, Isohanni M, Häkkinen U, Leinonen E. Change in antipsychotic usage pattern and risk of relapse in older patients with schizophrenia. Int J Geriatr Psychiatry. 2013;28:1305-11.

38. Cho UJ, Lee J, Kim HW, et al. Age structure at diagnosis affects aggression in a psychiatric inpatient population: age structure affecting inpatient aggression. Psychiatry Res. 2014;220:1059-63.

\section{Publisher's Note}

Springer Nature remains neutral with regard to jurisdictional claims in published maps and institutional affiliations.

Ready to submit your research? Choose BMC and benefit from:

- fast, convenient online submission

- thorough peer review by experienced researchers in your field

- rapid publication on acceptance

- support for research data, including large and complex data types

- gold Open Access which fosters wider collaboration and increased citations

- maximum visibility for your research: over $100 \mathrm{M}$ website views per year

At BMC, research is always in progress.

Learn more biomedcentral.com/submissions 